\title{
(2) OPEN ACCESS \\ From what we know to what we do: enhancing absorptive capacity in translational health research
}

\author{
Graeme Currie 도 , Tina Kiefer, Dimitrios Spyridonidis
}

Warwick Business School, University of Warwick, Coventry, UK

\section{Correspondence to}

Dr Graeme Currie, Warwick Business School, University of Warwick, Coventry CV4 7AL, UK; graeme.currie@wbs.ac.uk

Received 2 July 2019 Revised 14 September 2019 Accepted 20 September 2019 Published Online First 12 November 2019
Check for updates

(c) Author(s) (or their employer(s)) 2020. Re-use permitted under CC BY. Published by BMJ.

To cite: Currie G, Kiefer T, Spyridonidis D. BMJ Leader 2020;4:18-20.

\section{ABSTRACT}

Background Globally, evidence about what works is slow to translate into frontline healthcare delivery. As a response, government policy has focused on translational health initiatives, such as the National Institute for Health Research funded Applied Research Collaborations in England. Concepts from organisation science prove useful to support such translational initiatives. We critique the application of two organisation science concepts linked to the broad domain of what is commonly termed 'knowledge mobilisation' in healthcare settings, specifically 'knowledge brokers' and 'absorptive capacity', to provide lessons for leaders of translational initiatives.

Results The presence of knowledge brokers to 'move from what we know to what we do' in healthcare delivery appears necessary but insufficient to have a system level effect. To embed knowledge brokers in the wider healthcare system so they draw on various sources of evidence to discharge their role with greatest effect, we encourage leaders of translational health research initiatives to take account of the concept of absorptive capacity (ACAP) from the organisation science literature. Leaders should focus on enhancing ACAP though development of 'co-ordination capabilities'. Such co-ordination capability should aim not just to acquire different types of evidence, but to ensure that all types of evidence are used to develop, implement and scale up healthcare delivery that best benefits patients. Specific co-ordination capabilities that support translation of evidence are: clinician involvement in research and its implementation; patient and public involvement in research and its implementation; business intelligence structures and processes at organisational and system level.

Conclusion Attention to the dimensions and antecedents of ACAP, alongside the implementation of the knowledge brokering solution, in translational health research initiatives, is likely to better ensure the latter's success.

\section{INTRODUCTION}

The gap between the production of evidence and service improvement is recognised as a challenge across the globe. This challenge has been characterised as a 'translation gap' consisting of two dimensions: T1 'the translation of basic and clinical research into ideas and products' and T2 'introducing those ideas and products into clinical practice'. This article is concerned with bridging the second of these dimensions, the T2 gap. ${ }^{1}$ Major translation initiatives have been developed to bridge this T2 gap in England, such as the recent investments in NHS Academic Health
Science Networks (AHSNs) and Applied Research Collaborations (ARCs) by the National Institute for Health Research (NIHR). Such translational health research investments are evident globally, for example, in the USA, by the Department of Veterans' Affairs Quality Enhancement Research Initiative. However, the T2 challenge persists stubbornly in both theory and practice. Studies have encouraged translational health research initiatives to encompass insight from organisation science generated by business school researchers. ${ }^{2}$ Within this article, we highlight two organisation science concepts linked to the broad domain of what is commonly termed 'knowledge mobilisation' in healthcare settings. ${ }^{3}$ First, we critique the introduction of knowledge brokers to support translational health research as necessary but insufficient. Following which, second, we introduce the concept of 'absorptive capacity', the enhancement of which is crucial to support knowledge brokers' roles in healthcare settings. We provide lessons for those leading translational health research initiatives, such as NIHR ARCs and NHS AHSNs.

\section{KNOWLEDGE BROKERS}

Many translational health research interventions rely on knowledge brokers, defined as those 'who get the right knowledge, into the right hands, at the right time'. ${ }^{4}$ For example, one of the first NIHR Collaborations for Leadership in Applied Health Research and Care instituted in 2008, relied on 'diffusion fellows', clinicians drawn from the frontline of service that worked into translational health research teams, to drive evidence-based service improvement. In such arrangements, a clinician is allocated workload to work into an academic research team to coproduce a study, and then works outwards to diffuse study findings into practice so service improvement ensues. ${ }^{5}$ However, as a solution it has proved of limited effectiveness because knowledge brokers are few and far between within the wider system and its constituent organisations lack capacity to absorb knowledge produced by research. ${ }^{6}$ We also highlight a narrow focus on brokering of research evidence, may mean other knowledge, such as the tacit knowledge of clinicians gleaned from their practice ${ }^{7}$ and patient or carer experience of care, necessary for service improvement is not utilised. To address the challenge of embedding knowledge brokers in the wider healthcare system so they draw on various sources of knowledge to discharge their role with greatest effect, we encourage leaders of translational health research initiatives to take account of the concept of absorptive capacity (ACAP) from the organisation science literature. 


\section{ABSORPTIVE CAPACITY}

ACAP describes an organisation's 'ability to identify, assimilate, and exploit knowledge from the environment'.

The concept of ACAP has been derived from studies in the private sector, but is increasingly being applied to examine variations in healthcare performance. ${ }^{9-12}$ The concept of ACAP can be applied to address the both the T1 and T2 translational gap.

There are four stages or dimensions around which we need to enhance ACAP of an organisation or system to effectively acquire and use evidence. First, knowledge needs to be acquired, from different sources. Healthcare organisations and systems are relatively strong in this regard; that is, the problem is not one acquiring knowledge. ${ }^{13}$ Rather, the problem remains threefold around the other dimensions of ACAP. Some knowledge is marginalised even as it is assimilated. ${ }^{14}$ Different sources of knowledge, even if assimilated, are not utilised or in ACAP terms, 'transformed' to develop and implement a service intervention, instead the status quo remains. Finally, even if transformation of knowledge does happen, evidencebased service improvement may remain local, and is not scaled up, or in ACAP terms 'exploited' for wider health gain because service interventions are not evaluated and lessons learnt not diffused.

The above gives rise to a gap between: (1) potential ACAPthe ability to acquire and assimilate knowledge and (2) realised ACAP - the ability to put newly acquired knowledge into action within the organisation through transformation (the development and piloting of an intervention) and exploitation (scaling up of that intervention). Such variance between potential and realised ACAP determines organisational performance. ${ }^{15}$

In order to move from potential to realised ACAP, both the organisation and its members need key capabilities to help bridge complex social systems. Those are called combinative capabilities and are an important antecedent to developing ACAP and addressing variance between potential and realised ACAP. There are three combinative capabilities: (1) systems, (2) socialisation and (3) co-ordination capabilities. Systems capabilities refer to formal knowledge exchange mechanisms, such as written policies, procedures and manuals designed to facilitate transfer of codified knowledge, but also to environmental incentives that shape priorities. Socialisation capabilities refer to cultural mechanisms that promote a shared way of doing things and collective interpretations of reality within organisations. Coordination capabilities refer to lateral forms of communication such as education and training, facilitating leadership, cross-functional interfaces, collaborative learning strategies and distinct liaison roles. Empirical studies in private sector settings show that that variation in combinative capabilities influences ACAP. The traditional interaction of systems and socialisation capabilities are thought to stymie ACAP, though our position does not rule out the potential that novel combinations may in fact have a more positive influence. For example, regarding systems capabilities, policy emphasis on translational health research initiatives may or may not be outweighed by effect of austerity and performance management regimes. Meanwhile, regarding socialisation capabilities, professional resistance to change can hinder innovation, but professional connectedness supports scale up. Moreover, coordination capabilities mediate the adverse effects of systems and socialisation capabilities on organisations pulling in knowledge, and so enhance ACAP. The different balances between combinative capabilities are critical to understanding the ACAP of contexts which knowledge brokers are working within. It is therefore clearly important to understand these combinations further, particularly the positive effect of coordination capabilities on ACAP. $^{16}$

\section{ACAP FOR TRANSLATIONAL HEALTH RESEARCH}

In drawing on theoretical insights about ACAP, there are a number of ways in which leaders of translational health initiatives might assure their interventions are more successful. This relies in particular on enhancing co-ordination capabilities. ${ }^{17} \mathrm{We}$ offer some specific suggestions.

In considering co-ordination capabilities, we need to ensure organisations and systems can encompass a range of knowledge beyond formal research evidence, specifically tacit knowledge held by clinicians gleaned from their practice and patient and carer experience of care. First, to ensure clinicians' knowledge informs service improvement, clinician involvement in the development, implementation and scale up of evidence-based service improvement through knowledge brokering roles undoubtedly remains an important component of enhancing coordination capability of healthcare organisations and systems. Such involvement allows assimilation of clinicians' internal, tacit knowledge that is gleaned from their everyday experience of delivering care with the external information acquired from 'hard' data collection systems around cost efficiency, clinical effectiveness and population health. As above, however, to move from potential to realised ACAP in a balanced way, requires clinician involvement at all stages of the decision-making process so that the knowledge they hold is transformed and exploited. Their role as knowledge brokers in formal translational health research structures facilitates this. Following which, as well as enhancing their capabilities, there also needs to be incentives and opportunities for clinicians to participate in translational research. ${ }^{18}$

Meanwhile, second, to ensure patient and carer experience of care informs service improvement, patient and public involvement (PPI) has an important role as a part of the necessary co-ordination capability. Importantly, this knowledge should not just be acquired, but assimilated with other, more traditional evidence about clinical effectiveness, cost efficiency and population health. However, PPI and the knowledge held by representatives is commonly marginalised during transformation and exploitation of evidence as more powerful actors hold sway. ${ }^{19}$ Managers within healthcare organisations should work to further integrate PPI mechanisms into all of knowledge mobilisation to improve their ACAP, and thus ensure all sources of evidence inform service improvement interventions and their scale up.

The more sources of relevant knowledge acquired and utilised the more likely service improvement ensues. In this light, the development of co-ordination capabilities should not just encompass clinician involvement and PPI, but, third, business intelligence structures and processes, to understand health at the population level and how existing services match (or not) this need. Organisations should recognise, however, this needs to go beyond information systems solutions, since the mobilisation of knowledge is 'peopled'. To further enhance co-ordination capability, data analysts within the organisation need to work in real time with managers and frontline clinicians as problems are identified to ensure service improvement is derived from robust data held within healthcare organisations and systems.

Finally, in considering where clinician involvement, PPI and business intelligence generate ACAP, organisations need to consider all four stages or dimensions of ACAP. The tendency, specifically in healthcare, is that different knowledge is acquired, but then not not utilised. ${ }^{13}$ Particularly crucial is the exploitation 
dimension of ACAP since healthcare organisations and systems are renowned for their failure to scale up evidence-based innovation. Those leading translational health research initiatives need to fully examine what's working, from whose perspective, what might we adapt as we scale up, and how we might glean resource for any potential scale up. ${ }^{18}$

In summary, attention to the dimensions and antecedents of ACAP, alongside the implementation of the knowledge brokering solution, in translational health research initiatives, is likely to better ensure the latter's success.

Acknowledgements This research was funded by the National Institute for Health Research (NIHR) Collaboration for Leadership in Applied Health Research and Care West Midlands (NIHR CLAHRC WM).

Contributors GC planned the study and GC, DS and TK collaborated in the reporting of the study. GC and TK undertook fieldwork and developed a tool for measuring absorptive capacity within NIHR CLAHRC WM, which underpins the manuscript. Meanwhile, DS undertook parallel fieldwork within NIHR CLAHRC NDL. $\mathrm{GC}$ is the guarantor for content.

Funding National Institute of Health Research, Collaborations for Leadership in Applied Health Research and Care (no grant number).

Disclaimer The views expressed in this article are those of the author(s) and not necessarily those of the NHS, the NIHR or the Department of Health and Social Care.

Competing interests None declared.

Patient consent for publication Not required.

Provenance and peer review Not commissioned; externally peer reviewed.

Open access This is an open access article distributed in accordance with the Creative Commons Attribution 4.0 Unported (CC BY 4.0) license, which permits others to copy, redistribute, remix, transform and build upon this work for any purpose, provided the original work is properly cited, a link to the licence is given, and indication of whether changes were made. See: https://creativecommons.org/ licenses/by/4.0/.

ORCID iD

Graeme Currie http://orcid.org/0000-0002-4825-9711

\section{REFERENCES}

1 Cooksey D. A review of UK health research funding. London: HM Treasury, 2006.

2 Currie G, El Enany N, Lockett A. Intra-professional dynamics in translational health research: the perspective of social scientists. Soc Sci Med 2014;114:81-8.
3 Ferlie E, Crilly T, Jashapara A, et al. Knowledge mobilization in healthcare organizations: a view from the resource-based view of the firm. Int J Health Policy Manag 2015;4:127-30.

4 Currie G, White L. Inter-professional barriers and knowledge brokering in an organizational context: the case of healthcare. Organization Studies 2012:33:1333-61.

5 Rowley E, Morriss R, Currie G, et al. Research into practice: collaboration for leadership in applied health research and care (CLAHRC) for Nottinghamshire, Derbyshire, Lincolnshire (NDL). Implement Sci 2012;7.

6 Rycroft-Malone J, Wilkinson JE, Burton CR, et al. Implementing health research through academic and clinical partnerships: a realistic evaluation of the collaborations for leadership in applied health research and care (CLAHRC). Implement Sci 2011;6.

7 Gabbay J, le May A. Mindlines: making sense of evidence in practice. Br J Gen Pract 2016;66:402-3.

8 Cohen WM, Levinthal DA. Absorptive capacity: a new perspective on learning and innovation. Adm Sci Q 1990;35:128-52.

9 Harvey G, Jas P, Walshe K. Analysing organisational context: case studies on the contribution of absorptive capacity theory to understanding inter-organisational variation in performance improvement. BMJ Qual Saf 2015;24:48-55.

10 Berta W, Teare GF, Gilbart E, et al. Spanning the know-do gap: understanding knowledge application and capacity in long-term care homes. Soc Sci Med 2010;70:1326-34.

11 Crilly T, Jashapara A, Trenholm S, et al. Knowledge mobilisation in healthcare organisations: synthesising evidence and theory using perspectives of organisational form, resource based view of the firm and critical theory NIHR SDO 09/1002/13. London: Her Majesty's Stationery Office, 2013.

12 Harvey G, Skelcher C, Spencer E, et al. Absorptive capacity in a Non-Market environment. Public Management Review 2010;12:77-97.

13 Croft C, Currie G. Enhancing absorptive capacity of healthcare organizations: The case of commissioning service interventions to avoid undesirable older people's admissions to hospitals. In: Swan J, Nicolini D, eds. Knowledge mobilization in healthcare. Oxford: Oxford University Press, 2016.

14 Todorova G, Durisin B. Absorptive capacity: Valuing a reconceptualization. Acad Manage Rev 2007:32:774-86.

15 Zahra SA, George G. Absorptive capacity: a review, reconceptualization, and extension. Acad Manage Rev 2002;27:185-203.

16 Van den Bosch FAJ, Volberda HW, de Boer M. Coevolution of firm absorptive capacity and knowledge environment: organizational forms and Combinative capabilities. Organization Science 1999;10:551-68.

17 Hotho JJ, Becker-Ritterspach F, Saka-Helmhout A. Enriching absorptive capacity through social interaction. British Journal of Management 2012;23:383-401.

18 Currie G, Spyridonidis D. Sharing leadership for diffusion of innovation in professionalized settings. Human Relations 2019;72:1209-33.

19 Croft C, Currie G, Staniszewska S. Moving from rational to normative ideologies of control over public involvement: a case of continued managerial dominance. $\mathrm{Soc} \mathrm{SC}$ Med 2016;162:124-32. 